\title{
DENSIDADE RELATIVA ÓTIMA DE LATOSSOLOS VERMELHOS PARA A PRODUTIVIDADE DE SOJA ${ }^{(1)}$
}

\author{
Amauri Nelson Beutler ${ }^{(2)}$, José Frederido Centurion ${ }^{(3)}$, Cassiano \\ Garcia Roque $^{(4)} \&$ Marcos Vieira Ferraz ${ }^{(5)}$
}

\begin{abstract}
RESUMO
A compactação do solo tem causado decréscimos na produtividade de soja, e os valores de densidade do solo a partir dos quais a produtividade decresce são pouco conhecidos. Assim, este trabalho objetivou avaliar a produtividade de soja (cv. Embrapa 48) em relação à densidade relativa (Dsr) de Latossolo Vermelho textura média (LVd) e argilosa (LVef). Em 2001/2002, foi realizado um experimento em casa de vegetação, com amostras coletadas nos dois solos na camada de 0,0-0,2 m, peneirados a $4,0 \mathrm{~mm}$, adubados e compactados em camadas de $3,0 \mathrm{~cm}$, em vasos de $20 \mathrm{~cm}$ de altura e $25 \mathrm{~cm}$ de diâmetro. Foram estabelecidos quatro níveis de compactação e dois de água no solo (tensão de 0,01 e 0,05 MPa), com três repetições. A soja foi semeada em novembro (duas plantas por vaso) e irrigada duas vezes ao dia. No segundo experimento, no campo (2002/2003), utilizou-se apenas o LVd que foi compactado por meio de passadas de trator com quatro pneus de mesma largura, estabelecendo-se cinco níveis de compactação, com quatro repetições. A soja foi semeada, em dezembro de 2002, no espaçamento de $0,45 \mathrm{~m}$ entre linhas e 20 plantas por metro. Foram determinadas a densidade do solo (Ds) e a Ds máxima pelo teste de Proctor, sendo a Dsr obtida por divisão da Ds pela Ds máxima. Na colheita, foi avaliada a produtividade de grãos. A Dsr ótima para a produtividade de soja, em casa de vegetação, foi superior no Latossolo Vermelho eutroférrico argiloso $(0,84)$, comparada à do Latossolo Vermelho caulinítico de textura média $(0,75)$, na tensão de água no solo de 0,01 MPa. No campo, a Dsr ótima para soja foi de 0,80.
\end{abstract}

Termos de indexação: compactação do solo, manejo do solo, Glycine max.

\footnotetext{
(1) Recebido para publicação em março de 2004 e aprovado em agosto de 2005.

(2) Pós-Doutorando do Departamento de Solos e Adubos da Faculdade de Ciências Agrárias e Veterinárias, Universidade Estadual Paulista - FCAV/UNESP. Via de Acesso Rod. Paulo Donato Castellane s/n, CEP 14884-900 Jaboticabal (SP). Bolsista da FAPESP. E-mail: amaurib@yahoo.com.br

(3) Professor Adjunto do Departamento de Solos e Adubos, FCAV/UNESP. Bolsista do CNPq. E-mail: jfcentur@fcav.unesp.br

(4) Doutorando do Departamento de Solos e Adubos, FCAV/UNESP. Bolsista da FAPESP. E-mail: cassianoroque@yahoo.com.br

(5) Mestrando do Departamento de Solos e Adubos, FCAV/UNESP.
} 


\title{
SUMMARY: OPTIMAL RELATIVE BULK DENSITY FOR SOYBEAN YIELD IN OXISOLS
}

\begin{abstract}
Soil compaction has led to reduced soybean yields, but the critical bulk density above which the yield decreases are poorly documented. Thus, this work aimed to evaluate the soybean yield ( $\mathrm{cv}$. Embrapa 48) in relation to the relative bulk density (Dsr) of a sandy loam (LVd) and a clayey Oxisol (LVef). A greenhouse experiment was carried out in 2001/ 02 with samples collected at the 0.0-0.2 m layer, sifted through a $4.0 \mathrm{~mm}$ sieve, fertilized and compacted in $0.03 \mathrm{~m}$ layers in 0.20 high and $0.25 \mathrm{~m}$ diameter pots. Four compaction and two water content levels (tension of 0.05 and $0.01 \mathrm{MPa}$ ) were evaluated in three replications. Soybean was sown in November (two plants per pot) and irrigated twice a day. In the second experiment on the field (2002/2003), only LVd was used and compacted by driving a $11 \mathrm{Mg}$ tractor with four equally wide $(0.40 \mathrm{~m})$ tires, establishing five compaction levels, with four replications. Soybean was sown in December 2002, spaced $0.45 \mathrm{~m}$ between lines and 20 plants per meter. The bulk density (Ds) and maximum Ds was determined by the Proctor test, and the Dsr was obtained by dividing Ds by the maximum Ds. The soybean yield was evaluated at harvest. Under a soil water tension of 0.01, the optimum Dsr for soybean yield under greenhouse conditions was greater in the clayey eutroferric Oxisol (0.84) compared to the clay loam caulinitic Oxisol (0.75). The optimum Dsr for field soybean yield was 0.80.
\end{abstract}

Index terms: soil compaction, soil management, Glycine max.

\section{INTRODUÇÃO}

O Brasil é o segundo maior produtor e exportador mundial de soja e, segundo previsão da Agrianual (2004), em 2009/10, será o maior produtor mundial, com destaque para a Região Centro-Oeste (cerrados), que, atualmente, é responsável por $47 \%$ da produtividade brasileira (Agrianual, 2004).

Para o seu cultivo, o manejo adequado do solo é uma das mais importantes etapas para o sucesso da cultura e para maximizar a rentabilidade, manter a estabilidade da produtividade e preservar o meio ambiente (Torres \& Saraiva, 1999).

O manejo inadequado do solo causa compactação excessiva, principalmente em solos mais argilosos do Brasil em que a mineralogia é predominantemente caulinítica, e por serem esses solos formados de partículas pequenas que podem ser encaixadas nos espaços formados pelas partículas maiores. Aliado a isso, a crescente adoção do sistema plantio direto (SPD) tem levado a uma compactação superficial (Silva et al., 2000) e a decréscimos significativos da produtividade. Isso se torna mais acentuado na região dos cerrados, em que as altas temperaturas e precipitações promovem a rápida decomposição da matéria orgânica, refletindo em menor estruturação e porosidade do solo e, conseqüentemente, em maior compactação. A compactação de origem antrópica é oriunda do tráfego de máquinas e equipamentos agrícolas sobre o solo e reduz a porosidade e aumenta a resistência à penetração. Segundo Carter (1990), essa é a principal forma de degradação do solo, visto que prejudica os processos físicos, químicos e biológicos.
O monitoramento da compactação do solo é uma ferramenta imprescindível ao planejamento das práticas de cultivo a serem adotadas, visando maximizar a rentabilidade agrícola (Torres \& Saraiva, 1999). A resistência do solo à penetração e a densidade do solo são utilizadas principalmente para definir níveis a partir dos quais o solo está compactado e requer medidas corretivas. Por ser a resistência do solo à penetração dependente da umidade, textura, mineralogia e matéria orgânica, a densidade do solo tem sido utilizada como propriedade de referência para monitorar a compactação do solo. Essa, por sua vez, depende do peso, da forma e distribuição do tamanho e arranjamento das partículas de solo, sendo a amplitude de valores para solos minerais de 1,1 a $1,6 \mathrm{Mg} \mathrm{m}^{-3}$, com valores superiores para solos arenosos (Kiehl, 1979).

Apesar de serem a resistência à penetração e a densidade do solo utilizadas para monitorar a compactação do solo, Arvidsson \& Håkansson (1991) e Håkansson \& Lipiec (2000) afirmam que essas propriedades não podem ser diretamente utilizadas para comparar o estado de compactação de solos diferentes. A propriedade denominada densidade relativa do solo (Dsr) tem sido utilizada para caracterizar o estado de compactação, que é menos influenciada pelas características dos minerais no solo e independe do tipo e granulometria do solo (Håkansson, 1990; Lipiec et al., 1991; Håkansson \& Lipiec, 2000), a qual elimina as diferenças de resposta das culturas entre solos. Essa consiste na divisão da densidade do solo atual pela densidade máxima do solo obtida pelo teste de Proctor (Carter, 1990). Dessa forma, a utilização da Dsr é uma forma 
de evitar essas diferenças entre os solos, permitindo compará-los quantitativamente, segundo Arvidsson \& Håkansson (1991).

Valores de Dsr acima de 0,86 são considerados elevados e prejudiciais ao desenvolvimento das culturas e abaixo de 0,80 podem afetar a produtividade de alguns cereais em conseqüência da redução da capacidade de armazenamento de água no solo (Lindstron \& Voorhees, 1994). Segundo Arvidsson \& Håkansson (1991), em geral, na Dsr de 0,86 são obtidas maiores produtividades, oscilando com as condições climáticas e culturas, sendo os resultados similares para os diferentes solos. Håkansson (1990) realizou cerca de 100 experimentos de campo com cevada, em solos com difererentes texturas e conteúdos de matéria orgânica, e verificou que a Dsr ótima esteve associada ao valor de 0,87. Carter (1990) constatou que a produtividade máxima de trigo e cevada esteve associada a Dsr de 0,81 em solo arenoso de clima temperado. No Brasil, estudos de Torres \& Saraiva (1999), em Latossolo Roxo cultivado dois anos com soja, em clima tropical, observaram que, a partir da Dsr de 0,84 e 0,87, ocorreu decréscimo da produtividade.

A hipótese deste trabalho é que a densidade relativa ótima a partir da qual a produtividade decresce varia entre os solos. Assim, este estudo objetivou avaliar a produtividade de soja em relação à densidade relativa de dois Latossolos.

\section{MATERIAL E MÉTODOS}

Este estudo foi desenvolvido na UNESP/FCAV, Jaboticabal (SP). Utilizou-se um Latossolo Vermelho distrófico típico textura média A moderado caulinítico hipoférrico (LVd) e Latossolo Vermelho eutroférrico típico textura argilosa A moderado caulinítico-oxídico (LVef) (Embrapa, 1999). A composição granulométrica foi determinada em amostras deformadas por meio da dispersão com $\mathrm{NaOH}\left(0,1 \mathrm{~mol} \mathrm{~L}^{-1}\right)$ e agitação lenta por $16 \mathrm{~h}$. O conteúdo de argila foi obtido pelo método da pipeta (Gee \& Bauder, 1986) (Quadro 1).
A densidade máxima do solo foi determinada em amostras deformadas coletadas na camada de 0,0$0,2 \mathrm{~m}$ e passadas em peneira de $4,0 \mathrm{~mm}$. Para tal, utilizou-se o teste Proctor normal com reuso de material (Nogueira, 1998). A determinação da densidade máxima consistiu da adição de um pouco de água à amostra, homogeneização, adição de solo até $1 / 3$ do cilindro de $10 \mathrm{~cm}$ por $12,73 \mathrm{~cm}\left(1.000 \mathrm{~cm}^{-3}\right)$ que foi submetido a 26 golpes de um soquete de $2,5 \mathrm{~kg}$ caindo à altura de $30,5 \mathrm{~cm}$, equivalente a uma pressão de $200 \mathrm{kPa}$. Em seguida, adicionou-se mais uma camada até atingir $2 / 3$ e depois outra até atingir a superfície do cilindro, procedendo da mesma forma para compactação. Nos pontos seguintes, adicionouse mais água até que se verificou ter a densidade do solo diminuído, sendo obtida a Ds máxima. Objetivou-se obter o ponto de máxima Ds e dois pontos acima e dois abaixo, para permitir um melhor ajuste do modelo estatístico.

A densidade relativa do solo (Dsr) foi obtida pela divisão da densidade do solo pela densidade máxima do solo obtida no teste de Proctor.

No ano agrícola 2001/2002, foi realizado o experimento em casa de vegetação. Para tal, foram coletadas amostras de solo na camada de $0,0-0,2 \mathrm{~m}$ e passadas em peneira de $4,0 \mathrm{~mm}$. Os solos foram adubados, segundo Raij et al. (1996), cuja análise química foi realizada, conforme Raij et al. (1987) (Quadro 2). A adubação consistiu de $0,750 \mathrm{~g} \mathrm{~m}^{-3}$ de calcário com PRNT $135 \%, 165 \mathrm{~g} \mathrm{~m}^{-3}$ de superfosfato simples e $42 \mathrm{~g} \mathrm{~m}^{-3}$ de cloreto de potássio, no LVef; e $0,185 \mathrm{~g} \mathrm{~m}^{-3}$ de calcário, $110 \mathrm{~g} \mathrm{~m}^{-3}$ de superfosfato simples e $42 \mathrm{~g} \mathrm{~m}^{-3}$ de cloreto de potássio, no LVd. Inicialmente, aplicou-se o calcário e, após 30 dias, os demais fertilizantes foram dissolvidos em água e aplicados com regador sobre o solo que foi, em seguida, homogeneizado. Em um $\mathrm{m}^{3}$, foi utilizada a adubação referente a $5 \mathrm{~m}^{2}$ no campo.

Efetuada a adubação, foram ajustados os conteúdos de água de 0,11 e $0,14 \mathrm{~kg} \mathrm{~kg}^{-1}$, no LVd, e de $0,24 \mathrm{e}$ $0,27 \mathrm{~kg} \mathrm{~kg}^{-1}$, no LVef, correspondentes aos conteúdos de água retida nas tensões de 0,05 e 0,01 MPa, respectivamente, os quais foram determinados previamente em câmaras de Richards, em amostras indeformadas (Klute, 1986). Utilizaram-se esses

Quadro 1. Características do Latossolo Vermelho textura média (LVd) e argilosa (LVef), na camada de 0,0-0,20 m

\begin{tabular}{|c|c|c|c|c|c|c|c|}
\hline Solo & Matéria orgânica & Argila & Silte & Areia & $\mathrm{Fe}_{2} \mathrm{O}_{3}{ }^{(1)}$ & $\mathrm{Al}_{2} \mathrm{O}_{3}$ & Densidade de partículas \\
\hline & $\mathrm{g} \mathrm{dm}^{-3}$ & 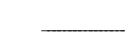 & 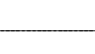 & $\mathrm{g} \mathrm{kg}^{-1}$ & 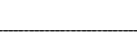 & - & $\mathrm{Mg} \mathrm{m}^{-3}$ \\
\hline $\mathrm{LVd}$ & 14 & 271 & 42 & 687 & 54 & 135 & 2,82 \\
\hline LVef & 37 & 517 & 256 & 227 & 205 & 235 & 2,98 \\
\hline
\end{tabular}

(1) Os teores de $\mathrm{Fe}_{2} \mathrm{O}_{3}$ e de $\mathrm{Al}_{2} \mathrm{O}_{3}$ foram determinados segundo Embrapa (1997). 
dois conteúdos de água por ser o conteúdo de água retida na tensão de $0,01 \mathrm{MPa}$ ideal ao crescimento das plantas e, na tensão de 0,05 Mpa, já ocorrerem perdas de produtividade por falta de água para as plantas, segundo Fernandes \& Turco (2003).

A operação de ajuste dos conteúdos predeterminados consistiu na adição de água ou secagem do solo quando muito úmido, até atingir o conteúdo de água prestabelecido, sendo, posteriormente, o solo coberto com lona plástica para evitar alteração no conteúdo de água do solo. Em seguida, o solo foi colocado em vaso cilíndrico de PVC com capacidade de 9,82 L (0,20 m de altura e 0,25 m de diâmetro), em camadas de $0,03 \mathrm{~m}$, que foram homogeneamente compactadas até à superfície do vaso. Cada camada foi compactada por meio da queda livre de um êmbolo de 7,0 kg, da altura de 0,60 m, no centro geométrico de um suporte de madeira com diâmetro ligeiramente inferior ao vaso, conforme descrito em Beutler (2003), sendo valores superiores de compactação obtidos por meio de maior número de impactos em cada camada (Quadro 3).

Os tratamentos consistiram de quatro níveis de compactação e dois conteúdos de água no solo, constituindo um experimento inteiramente casualizado, em esquema fatorial $4 \times 2$, com três repetições e mais duas repetições que foram utilizadas apenas para avaliações físicas do solo.

Em novembro de 2001, foram semeadas três sementes de soja (Glycine max cv. Embrapa 48) inoculadas por cova (quatro covas por vaso). Após sete dias, realizou-se o desbaste, deixando duas plantas por vaso. Nesta data, foram aplicados os tratamentos de umidade predeterminados (tensões de 0,01 e 0,05 MPa), visto que foi necessário utilizar maior conteúdo de água, nesses sete dias, para possibilitar a germinação nos vasos mais secos e compactados. O conteúdo de água foi mantido constante, após duas pesagens diárias dos vasos referentes a uma repetição e reposição de água através de tubo de PVC perfurado, instalado no centro geométrico do vaso, conforme demonstrado em Beutler (2003); a pesagem e o rodízio dos vasos foram feitos a cada cinco dias. Na colheita, foi avaliada a produtividade de grãos de soja por planta com umidade ajustada a $0,12 \mathrm{~kg} \mathrm{~kg}^{-1}$.

No segundo experimento, realizado no campo, em 2002/2003, nas coordenadas geográficas de $21^{\circ} 15^{\prime}$, 29 " S e $48^{\circ} 16^{\prime} 53^{\prime}$ W, e altitude média de $607 \mathrm{~m}$, utilizou-se apenas o LVd. O regime climático do local é Cwa, de acordo com o sistema de Köppen-Geige.

Antes da instalação desse experimento, foi realizada uma escarificação do solo até $0,30 \mathrm{~m}$ de profundidade, seguido de uma gradagem. Na seqüência, quando o conteúdo de água no solo estava próximo à capacidade de campo $(-0,01 \mathrm{MPa})$, foram realizados os tratamentos de compactação: $\mathrm{T}_{0}=0$; $\mathrm{T}_{1}=1 ; \mathrm{T}_{2}=2 ; \mathrm{T}_{4}=4$ e $\mathrm{T}_{6}=$ seis passagens, no mesmo local, de um trator de $11 \mathrm{t}$ com os quatro pneus de mesma largura $(0,40 \mathrm{~m})$ e pressão interna, uma ao lado da outra, perfazendo toda a superfície do solo. O delineamento experimental foi inteiramente casualizado com cinco níveis de compactação e quatro repetições constituídas por parcelas úteis de $3,6 \mathrm{~m}^{2}$.

$\mathrm{Na}$ semeadura, o solo foi adubado no sulco, segundo Raij et al. (1996); $50 \mathrm{~kg} \mathrm{ha}^{-1}$ de sulfato de amônio, $125 \mathrm{~kg} \mathrm{ha}^{-1}$ de superfosfato triplo e $85 \mathrm{~kg} \mathrm{ha}^{-1}$ de cloreto de potássio, para obtenção da produtividade esperada de $2,5-2,9 \mathrm{t} \mathrm{ha}^{-1}$, cuja análise química foi realizada, conforme Raij et al. (1987) (Quadro 2).

Em dezembro de 2002, foi semeada a soja (cv. Embrapa 48), na profundidade de $0,05 \mathrm{~m}$ e espaçamento de $0,45 \mathrm{~m}$ entre linhas, com semeadora de cinco linhas para plantio direto. Foi realizado o desbaste 10 dias após a semeadura, deixando 20 plantas por metro linear. O controle de plantas invasoras foi manual. Na colheita, foi avaliada a produtividade de grãos de soja por hectare, a partir da parcela útil de $3,6 \mathrm{~m}^{2}$.

Após a semeadura, foram coletadas amostras, com duas repetições em cada nível de compactação, com cilindros de $53,16 \mathrm{~cm}^{3}$ na camada de $0,02-$ $0,05 \mathrm{~m}$ para o experimento em casa de vegetação.

Quadro 2. Características químicas do Latossolo Vermelho textura média (LVd) e argilosa (LVef), na camada de 0,0-0,20 m, antes da adubação

\begin{tabular}{|c|c|c|c|c|c|c|c|}
\hline Solo & $\mathrm{pH}\left(\mathrm{CaCl}_{2}\right)$ & Matéria orgânica & $\mathbf{P}_{\text {resina }}$ & $\mathbf{K}$ & $\mathbf{C a}$ & Mg & $\mathbf{V}$ \\
\hline & $1: 2,5$ & $\mathrm{~g} \mathrm{dm}{ }^{-3}$ & $\mathrm{mg} \mathrm{dm}^{-3}$ & \multicolumn{3}{|c|}{$\mathrm{mmol}_{\mathrm{c}} \mathrm{dm}^{-3}$} & $\%$ \\
\hline \multicolumn{8}{|c|}{ Casa de vegetação } \\
\hline $\mathrm{LVd}$ & 5,2 & 14 & 18 & 1,2 & 14 & 10 & 52 \\
\hline LVef & 4,8 & 37 & 16 & 1,2 & 21 & 10 & 41 \\
\hline \multicolumn{8}{|c|}{ Campo } \\
\hline LVd & 5,0 & 13,5 & 19 & 2,0 & 15 & 7 & 53 \\
\hline
\end{tabular}


No experimento de campo, foram coletadas amostras nas camadas de $0,02-0,05 ; 0,07-0,10$ e $0,15-0,18 \mathrm{~m}$, das quais se utilizou a média.

No campo, foram coletadas amostras em três profundidades para representar melhor a compactação na camada de $0,0-0,20 \mathrm{~m}$, fato não necessário nos vasos em casa de vegetação, pois a compactação em camadas permite uma compactação uniforme em toda a camada de $0,0-0,20 \mathrm{~m}$.

Essas amostras foram secas em estufa a $\pm 105^{\circ} \mathrm{C}$, durante $24 \mathrm{~h}$, e pesadas para determinação da densidade do solo (Quadro 3) (Blake \& Hartge, 1986).

Os resultados foram submetidos à análise de variância e, quando significativa, foi efetuada a análise de regressão entre a Dsr com a produtividade de grãos de soja, por meio do programa estatísitico SAS (SAS, 1996).

\section{RESULTADOS E DISCUSSÃO}

Verificou-se que a máxima compactação do solo foi obtida no conteúdo de água retida próximo à capacidade de campo $\left(0,14\right.$ e $0,27 \mathrm{~kg} \mathrm{~kg}^{-1}$; LVd e LVef, respectivamente, na tensão de 0,01 MPa), condição em que deve ser evitado o tráfego de máquinas sobre o solo (Figura 1). Já em menor conteúdo de água no solo ocorre menor compactação, por causa das partículas que se aglutinam por forças de coesão, formando microagregados mais resistentes, que impedem o deslocamento das partículas e seu rearranjamento e conseqüente compactação (Nogueira, 1998). No estudo em casa de vegetação, porém, verificam-se valores próximos de Ds nos tratamentos em que o solo foi compactado a 0,05 e 0,01 MPa, porque foi utilizado menor número de impactos quando o solo estava mais úmido $(0,01 \mathrm{MPa})$. Isto porque o objetivo foi obter níveis semelhantes de densidade do solo para um mesmo nível de compactação.

No experimento de campo, foram obtidos valores de Ds superiores aos obtidos em vasos no LVd (Quadro 3), tendo sido, em ambos os experimentos, o solo compactado no conteúdo de água de $-0,01 \mathrm{MPa}$, visto que no experimento de campo foram aplicadas pressões superiores às do experimento em casa de vegetação.

A Dsr ótima para produtividade de soja obtida no LVef $(0,84)$ foi ligeiramente superior comparada à do $\operatorname{LVd}(0,75)$, no conteúdo de água retida na tensão de 0,01 MPa (Figura 2), sendo tal resultado contraditório aos estudos de Håkansson (1990) e Arvidsson \& Håkansson (1991) e à revisão de literatura de Håkansson \& Lipiec (2000). Esses pesquisadores relatam que a Dsr ótima é semelhante entre diferentes solos com composição granulométrica diferenciada. Essa diferença para os solos tropicais está relacionada com o fato de o solo LVef apresentar mineralogia oxídica que condiciona a formação de uma estrutura granular forte muito pequena e com maior espaço poroso (Ferreira et al., 1999), comparado ao LVd caulinítico com estrutura maciça. Assim, a Dsr ótima à produtividade de soja foi superior no LVef, corroborando com Veen et al. (1992), que afirmam que solos soltos e porosos apresentam menor condutividade hidráulica do solo não saturado e menor contato das raízes com o solo, influenciando negativamente a absorção de água e nutrientes.

Em relação à Ds máxima, o valor foi de $1,85 \mathrm{Mg} \mathrm{m}^{-3}$, para o LVd, e de $1,54 \mathrm{Mg} \mathrm{m}^{-3}$, para o

Quadro 3. Valores de densidade do solo, considerando o nível de compactação dos Latossolos Vermelhos, em casa de vegetação e no campo

\begin{tabular}{|c|c|c|c|c|}
\hline \multirow{2}{*}{ Nível de compactação } & \multicolumn{2}{|c|}{ LVd } & \multicolumn{2}{|c|}{ LVef } \\
\hline & 0,01 MPa & 0,05 Мра & 0,01 MPa & $0,05 \mathrm{MPa}$ \\
\hline & \multicolumn{4}{|c|}{ Densidade do solo, $\mathrm{Mg} \mathrm{m}^{-3}$} \\
\hline & \multicolumn{4}{|c|}{ Casa de vegetação } \\
\hline 1 & 1,05 & 1,05 & 1,01 & 1,01 \\
\hline 2 & 1,43 & 1,46 & 1,24 & 1,20 \\
\hline 3 & 1,54 & 1,51 & 1,28 & 1,24 \\
\hline \multirow[t]{2}{*}{4} & 1,59 & 1,54 & 1,39 & 1,30 \\
\hline & \multicolumn{4}{|c|}{ Campo } \\
\hline $\mathrm{T}_{0}^{(1)}$ & & & & \\
\hline $\mathrm{T}_{1}$ & & & & \\
\hline $\mathrm{T}_{2}$ & & & & \\
\hline $\mathrm{T}_{4}$ & & & & \\
\hline $\mathrm{T}_{6}$ & & & & \\
\hline
\end{tabular}

\footnotetext{
$\overline{{ }^{(1)}} 0,1,2,4,6$ passadas de trator no mesmo local, no conteúdo de água próximo à capacidade de campo (-0,01 MPa).
} 
LVef (Figura 1). Esse valor superior para o LVd deve-se à granulometria e ao tipo de mineral nesse solo, predominantemente quartzo e caulinita, que conferem menor porosidade a esse solo, segundo Ferreira et al. (1999). Além da maior Ds máxima do LVd, a Ds em que foi obtida a maior produtividade também foi superior $\left(1,40 \mathrm{Mg} \mathrm{m}^{-3}\right)$, quando comparada à do LVef $\left(1,29 \mathrm{Mg} \mathrm{m}^{-3}\right)$, na tensão de 0,01 MPa (Figura 2). Porém, a Dsr ótima para obtenção de maior produtividade de soja foi ligeiramente inferior no LVd, comparada, à do LVef, em casa de vegetação (Figura 2).

Ainda, a Dsr ótima à produtividade de grãos de soja foi influenciada pelo conteúdo de água no solo. No experimento em casa de vegetação, a Dsr ótima foi inferior nos dois solos, no menor conteúdo de água (tensão 0,05 MPa), possivelmente relacionado com a disponibilidade de água para o crescimento das plantas.

Por sua vez, no LVd, em casa de vegetação, obtevese valor de Dsr ótima inferior, nos dois conteúdos de água, comparado ao experimento de campo. Isso pode ter ocorrido em decorrência dos períodos de umedecimento e secagem que ocorreram durante o dia no experimento em casa de vegetação, submetendo as plantas a períodos com menor conteúdo de água no solo, comparado ao campo, em

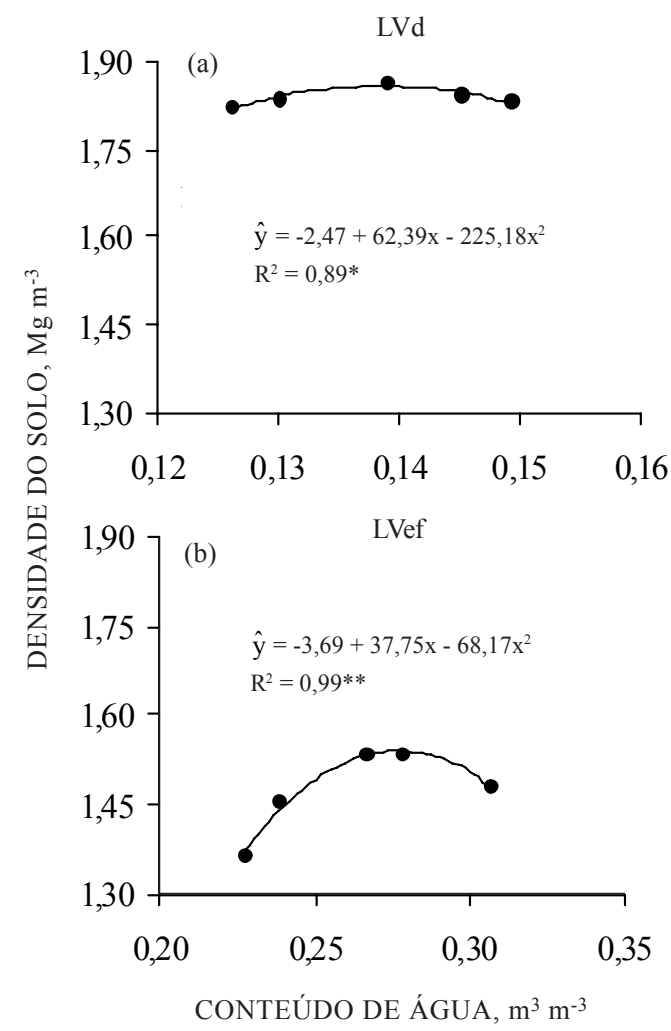

Figura 1. Densidade máxima determinada com o aparelho de Proctor, no (a) Latossolo Vermelho textura média (LVd) e (b) argilosa (LVef). **, * Significativos a 1 e $5 \%$, respectivamente. que o conteúdo de água é mantido mais constante durante o dia. Neste contexto, Fernandes \& Turco (2003) verificaram que a freqüência de irrigação foi mais importante do que a quantidade de água aplicada, para a produtividade de soja.

Os valores de Dsr ótima para produtividade de soja no LVd, no campo $(0,80)$ (Figura 3), está próximo ao mencionado na literatura como ótimo para a obtenção de produtividades máximas (Lindstron \& Voorhees, 1994; Carter, 1990). Torres \& Saraiva

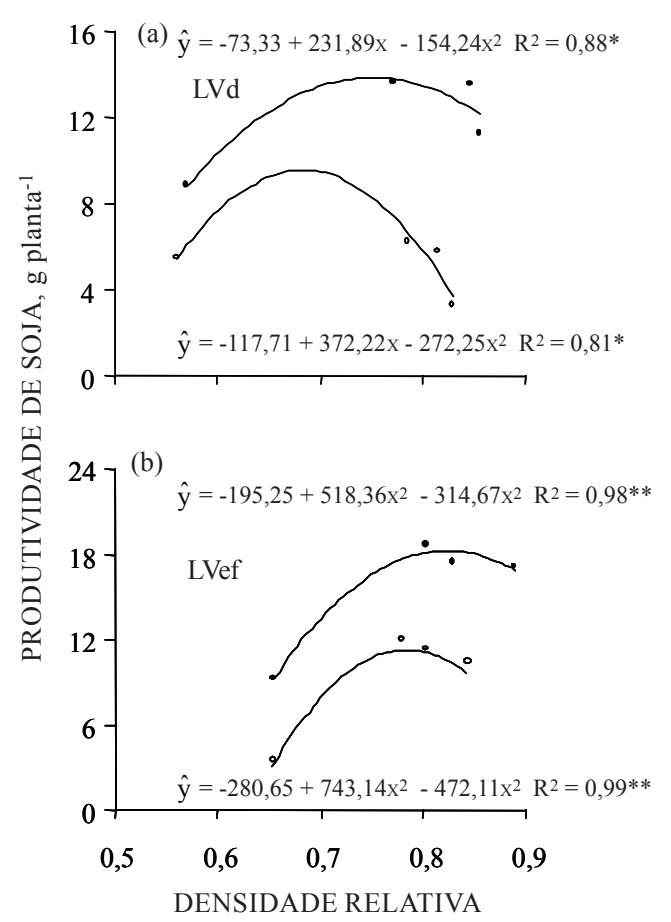

Figura 2. Regressão entre a densidade relativa do solo e a produtividade de grãos de soja, em casa de vegetação, no (a) Latossolo Vermelho de textura média (LVd) e (b) argiloso (LVef), na tensão de 0,01 (•) e $0,05 \mathrm{MPa}(\mathrm{o})$. **, * Significativos a 1 e $5 \%$, respectivamente.

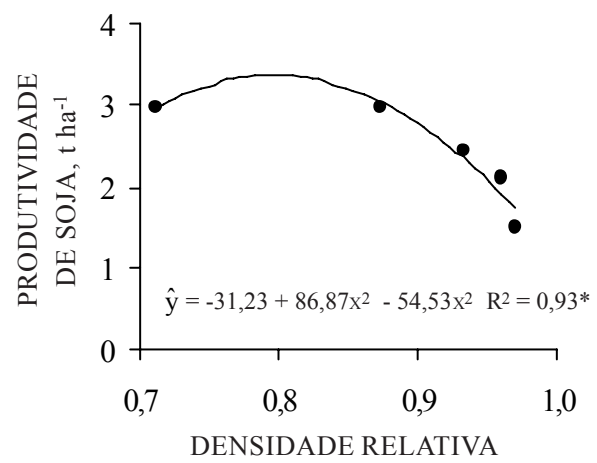

Figura 3. Regressão entre a densidade relativa do solo e a produtividade de grãos de soja, no campo, no Latossolo Vermelho de textura média. * Significativo a $5 \%$. 
(1999), em solo tropical, verificaram que a produtividade de soja decresceu a partir da Dsr de 0,84 e 0,87, para os anos agrícolas de 1985/86 e 1987/ 88, respectivamente, em Latossolo Roxo.

\section{CONCLUSÕES}

1. A densidade relativa do solo (Dsr) ótima para a produtividade de soja foi superior no Latossolo Vermelho eutroférrico argiloso $(0,84)$, comparado ao Latossolo Vermelho caulinítico de textura média $(0,75)$, na tensão de água no solo de $0,01 \mathrm{MPa}$, em casa de vegetação.

2. No campo, a Dsr ótima para a produtividade de soja no $L V d$ foi de 0,80 .

\section{LITERATURA CITADA}

AGRIANUAL 2004: Anuário da agricultura brasileira. São Paulo, FNP Consultoria e Comércio, 2004. p.421-462.

ARVIDSSON, J. \& HÅKANSSON, I. A Model for estimating crop yield losses caused by soil compaction. Soil Till. Res., 20:319-332, 1991.

BEUTLER, A.N. \& CENTURION, J.F. Efeito do conteúdo de água e da compactação do solo na produtividade de soja. Pesq. Agropec. Bras., 38:849-856, 2003.

BEUTLER, A.N. Efeito da compactação do solo e do conteúdo de água nas características agronômicas de soja e arroz de sequeiro. Jaboticabal, Universidade Estadual Paulista, 2003. 126p. (Tese de Doutorado)

BLAKE, G.R. \& HARTGE, K.H. Bulk density. In: KLUTE, A., ed. Methods of soil analysis: Physical and mineralogical methods. 2.ed. Madison, American Society of Agronomy, 1986. v.1. p.363-375.

CARTER, M.R. Relative measures of soil bulk density to characterize compaction in tillage studies on fine sandy loams. Can. J. Soil Sci., 70:425-433, 1990.

EMPRESA BRASILEIRA DE PESQUISA AGROPECUÁRIA EMBRAPA. Centro Nacional de Pesquisa de Solos. Sistema Brasileiro de Classificação de Solos, Brasília, Produção de Informação, Rio de Janeiro, Embrapa Solos, 1999. 412p.

EMPRESA BRASILEIRA DE PESQUISA AGROPECUÁRIA EMBRAPA. Centro Nacional de Pesquisa de Solos. Manual de Métodos de Análise de Solo. Rio de Janeiro, Embrapa Solos, 1997. p.125-134.

FERNANDES, E.J. \& TURCO, J.E.P. Evapotranspiração de referência para manejo da irrigação em cultura de soja. Irriga, 8:132-141, 2003.
FERREIRA, M.M.; FERNANDES, B. \& CURI, N. Mineralogia da fração argila e estrutura de Latossolos da região sudeste do Brasil. R. Bras. Ci. Solo, 23:507-514, 1999.

GEE, G.W. \& BAUDER, J.W. Particle-size analysis. In: KLUTE, A., ed. Methods of soil analysis. 2.ed. Madison, American Society of Agronomy, 1986. v.1. p.383-411.

HÅKANSSON, I. \& LIPIEC, J. A rewiew of the usefulness of relative bulk density values in studies of soil structure and compaction. Soil Till. Res., 53:71-85, 2000.

HÅKANSSON, I. A method for characterizing the state of compactness of the plough layer. Soil Till. Res., 16:105-120, 1990.

KIEHL, E.J. Manual de edafologia: Relações solo-planta. São Paulo, Ceres, 1979. 264p.

KLUTE, A. Water retention: Laboratory methods. In: KLUTE, A., ed. Methods of soil analysis. 2. ed. Madison, American Society of Agronomy, 1986. v.1. p.635-662.

LINDSTRON, M.J. \& VOORHEES, W.B. Response of temperate crops to soil compaction. In: SOANE, B.D. \& van OUWERKERK, C. Soil compaction in crop production. London, Elsevier, 1994. p.265-286. (Developments in Agricultural Engineering, 2)

LIPIEC, J.; HÅKANSSON, I.; TARKIEWICZ, S. \& KOSSOWSKI, J. Soil physical properties and growth of spring barley as related to the degree of compactness of two soils. Soil Till. Res., 19:307-317, 1991.

NOGUEIRA, J.B. Mecânica dos solos. Ensaios de Laboratório. São Carlos, EESC-USP, 1998. 248p.

RAIJ, B. van; CANTARELLA, H.; QUAGGIO, J.H. \& FURLANI, A.M.C. Recomendação de adubação e calagem para o Estado de São Paulo. 2.ed. Campinas, Instituto Agronômico de Campinas, 1996. 285 p. (Boletim Técnico, 100)

RAIJ, B. van; QUAGGIO, J.A.; CANTARELLA, H.; FERREIRA, M.E.; LOPES, A.S. \& BATAGLIA, O.C. Análise química do solo para fins de fertilidade. Campinas, Fundação Cargill, 1987. 170 p.

SAS INSTITUTE. SAS/STAT procedure guide for personal computers. 5.ed. Cary, 1996. 1686p.

SILVA, V.R.; REINERT, D.J. \& REICHERT, J.M. Resistência mecânica do solo à penetração influenciada pelo tráfego de uma colhedora em dois sistemas de manejo do solo. Ci. Rural, 30:795-801, 2000.

TORRES, E. \& SARAIVA, O.F. Camadas de impedimento do solo em sistemas agrícolas com a soja. Londrina, Embrapa Soja, 1999. 58p. (Circular Técnica, 23)

VEEN, B.W.; van NOORDWIJD, M.; DE WILLIGEN, P.; BOONE, F.R. \& KOOISTRA, M.J. Root-soil contact of maize, as measured by a thin-section technique. Plant Soil, 139:131-138, 1992. 